Barbara Trygar

(D)https://orcid.org/0000-0001-5125-624X

Uniwersytet Rzeszowski

Rzeszów, Polska

\title{
„Parcours de la reconnaissance". \\ 120 dni „Kultury” Wojciecha Karpińskiego w kontekście dialektyczności podmiotu Paula Ricoeura
}

\author{
"Parcours de la reconnaissance." 120 Days of "Culture" \\ by Wojciech Karpiński in the Context \\ of Paul Ricoeur's Dialectic of the Subject
}

Abstract: The article analyses Wojciech Karpiński's latest book titled 120 dni „Kultury” in the context of Paul Ricoeur's philosophy of man. Karpiński chose texts published in "Kultura", a Parisian literary magazine, from writers who inspired him the most, taught him how to look at the world and at other people, and above all showed him how to discover the beauty of art. Karpiński's I' was shaped by his encounter with other artists. Narrative identity is a bridge leading to the concept of open dialectics proposed by the French philosopher, which combines two methods. One involves the researcher adopting an a posteriori approach, starting from the concrete, i.e. the individual subject located in specific realities of life, immersed in a specific culture, having their own history and experiences. For the other, the researcher uses a Kantian turn, reflecting on the subject in a transcendental perspective. Subjectivity means turning towards the Other, and thanks to the Other, one transcends oneself. As Ricoeur argues, there is an "ontological force" in language that points to a certain way of being-inthe-world. Identity is consciously transformed, and literature is simultaneously an artistic record of this movement and a cultural-anthropological discourse.

Keywords: $\quad$ Wojciech Karpiński, subjectivity, Paul Ricoeur's philosophy, "Kultura", Other

Abstrakt: W W artykule analizuję ostatnią książkę Wojciecha Karpińskiego pt. 120 dni „Kultury” w kontekście filozofi człowieka Paula Ricoeura. Karpiński wybrał publikowane w paryskiej „Kulturze” teksty pisarzy, którzy go najbardziej inspirowali, uczyli patrzenia na świat i na drugiego człowieka, a przede wszystkim pokazywali, jak odkrywać piękno sztuki. „Ja”KKarpińskiego kształtowało się w spotkaniu z innymi artystami. Tożsamość narracyjna jest pomostem prowadzącym do zaproponowanej przez francuskiego filozofa koncepcij otwartej dialektyki, którałączy dwa podejścia. Po pierwsze badacz przyjmuje porządek aposterioryczny, wychodząc od konkretu, czyli jednostkowego podmiotu umiejscowionego w określonych realiach życiowych, zanurzonego w konkretnej kulturze, posiadającego własną historię i doświadczenia, po drugie posługuje się kantowskim zwrotem, prowadząc refleksję o podmiocie w perspektywie transcendentalnej. Podmiotowość to zwrócenie 
się ku Innemu, a dzięki Innemu dokonuje się transcendowanie siebie. Jak dowodzi francuski filozof, w języku istnieje „siła ontologiczna", która wskazuje na określony sposób bycia-w-świecie. Tożsamość podlega świadomym przeobrażeniom, a literatura jest artystycznym zapisem tego ruchu i zarazem dyskursem kulturowo-antropologicznym.

Słowa kluczowe: Wojciech Karpiński, tożsamość, filozofia Paula Ricoeura, ,IKultura" paryska, Inny

Wojciech Karpiński codziennie od 30 marca 2020 roku przez 120 dni o godzinie 16.00 publikował fragmenty paryskiej „Kultury” na stronie Association Institut Littéraire Kultura - (Home/Facebook $)^{1}$. Materiał został ułożony w tygodniowe cykle tematyczne. Powstała $\mathrm{z}$ tego antologia, a jednocześnie samodzielny, nieskończenie bogaty utwór, wypełniony świadectwami innych artystów, pantekst kultury, który Karpiński opatrzył tytułem 120 dni „Kultury”. Jest to ostatnia praca pisarza, bardzo ważna, stanowi bowiem próbę odpowiedzi na pytanie o parcours de la reconnaissance ${ }^{3}$, czyli drogi rozpoznania siebie jako pisarza, eseisty, krytyka w konfrontacji z głosami innych artystów:

Kierowałem się wyraźnym kryterium. Wybierałem te teksty, które przemawiały do mnie w latach młodości, uczyły, jak patrzeć na świat, jak żyć, jak

${ }^{1}$ Associaton Institut Littéraire Kultura, 91 Avenue de Poissy, 78600 Le Mesnil-le-Roi, France. Strona internetowa: https://kulturaparyska.com/pl/index [dostęp: 12.04.2021]. Association Institut Littéraire Kultura, Le Mesnil-le-Roi, France (Stowarzyszenie Instytut Literacki Kultura - Home/Facebook).

${ }^{2}$ Antologia jest dostępna w formie e-booka na stronie Wojciecha Karpińskiego: http://www.wojciechkarpinski.com/120-dni-kultury [dostęp: 12.04.2021].

${ }^{3}$ Zwrot zapośredniczony z pracy Parcours de la reconnaissance Paula Ricoeura w tłumaczeniu Janusza Margańskiego brzmi: Drogi rozpoznania. Tak zatytułowane były trzy wykłady francuskiego filozofa wygłoszone w L'Institut für die Wissenschaften vom Menschen de Vienne, a następnie w Centre des Archives Husserl à Vienne. Tekst został opublikowany w 2004 roku przez wydawnictwo Stock w Paryżu. Tematy wykładów: Première étude. La reconnaissance comme identification (Pierwsze badanie. Uznanie jako identyfikacja); Deuxième étude. Se reconnaître soi-même (Drugie badanie. Rozpoznaj siebie); Troisième étude. La reconnaissance mutuelle (Trzecie badanie. Wzajemne uznawanie) (Ricoeur 2004a. Zob. Ricoeur 2004b). 
być bogatszym, swobodniejszym, i które po przeszło półwieczu zachowują nadal siłę oddziaływania. Dziękowałem mistrzom mojej młodości za dar, który od nich otrzymałem. Teraz chciałbym przekazać go dalej. Po raz kolejny utwierdziłem się w przekonaniu o bogactwie, które tkwi w polskim piśmiennictwie drugiej połowy XX wieku (Karpiński 2020, 10).

Książka ta jest dla jej twórcy rodzajem dialogicznej próby określenia swojego projektu antropologicznego. Aby dobrze odczytać koncept Karpińskiego, należy przybliżyć w tym miejscu najważniejsze wydarzenia z życia pisarza. Tożsamość - podobnie jak inne konstrukty kulturowe - jest w ruchu, podlega ciągłym przeobrażeniom pod wpływem doświadczeń życiowych.

Wojciech Karpiński urodził się 11 maja 1943 roku w Warszawie. Studiował romanistykę (w 1966 roku obronił pracę dyplomową) i filozofię na Uniwersytecie Warszawskim, gdzie od 1967 roku prowadził zajęcia z literatury francuskiej. Podczas wyjazdu na Zachód w latach sześćdziesiątych poznał pisarzy, którzy mieli duży wpływ na jego twórczość: Aleksandra Wata, Konstantego Jeleńskiego Józefa Czapskiego, Witolda Gombrowicza, Gustawa Herlinga-Grudzińskiego, Jerzego Stempowskiego, Czesława Miłosza. Większość z nich była związana ze środowiskiem „Kultury” paryskiej. Pod wpływem tych spotkań podjął się zadania popularyzacji i interpretacji utworów „pisarzy zbójeckich”, jak ich sam określił. Czerpał z kulturowego dziedzictwa, pisał o świecie, który już istniał, o zjawiskach już uformowanych, po to, aby je odczytać w nowym kontekście kulturowym, odkryć jeszcze to, co zostało niewypowiedziane czy niezinterpretowane. W latach 1971-1973 był sekretarzem Komitetu Neofilologicznego Polskiej Akademii Nauk. Na zaproszenie U.S. International Agency (Educational and Cultural Agency) w 1981 roku wyjechał do Stanów Zjednoczonych, gdzie prowadził wykłady na Yale University (1982), University of Texas (1990) i New York University (1994-1995). Od 1982 roku mieszkał we Francji, gdzie współpracował z komitetem wykonawczym Funduszu Pomocy Niezależnej Literaturze i Nauce Polskiej w Paryżu (do 2002 roku). W latach 1982-2008 pracował w Centre National de la Recherche Scientifique w Paryżu. Zmarł nagle 18 sierpnia 2020 roku w Paryżu. 
Zadebiutował w 1964 roku na łamach „Kwartalnika Neofilologicznego" szkicem o François de La Rochefoucauld. W maju 1970 roku opublikował pod pseudonimem Zenon Mielnicki ${ }^{4}$ swój pierwszy tekst w paryskiej „Kulturze” pt. W polskich oczach. Warto też przypomnieć, że w latach 1972-1979 redagował rubrykę „Literatura francuska” w „Pamiętniku Literackim”, a w połowie lat siedemdziesiątych współpracował z działem „Tematy i refleksje” zawartym w „Tygodniku Powszechnym”. Praca na stanowisku redaktora stanowiła ważną część jego życia, w roku 1974 został powołany do zespołu miesięcznika „Twórczość”, pięć lat później z Marcinem Królem założył pismo „Res Publica”. Od 1982 roku był członkiem redakcji „Zeszytów Literackich”. Brał czynny udział w wydaniu w Polsce esejów Jerzego Stempowskiego i Konstantego A. Jeleńskiego, również z jego inicjatywy Paweł Hertz przetłumaczył i opublikował po raz pierwszy w Polsce zbiór szkiców Hugo von Hofmannsthala a także Rosję w roku 1839 Astolphe'a de Custine. Karpiński podkreślał $\mathrm{w}$ redagowanych dziełach pisarzy wartość podejmowanych tematów, „doskonałość wyrazu”, retoryczną i stylistyczną sprawność utworów, ciekawe rozplanowanie tekstowych impulsów. Z kolei zagadnienia związane z polityką, demokracją, wolnością zreferował w opracowanych wraz z Marcinem Królem Sylwetkach politycznych XIX wieku (1974), które później ukazały się w wersji rozszerzonej pod tytułem Od Mochnackiego do Piłsudskiego. Sylwetki polityczne XIX wieku (1997). Inne prace z tego zakresu to: Szkice o wolności (1980), Słowiański spór (1981), Cień Metternicha (1982), Prywatna historia wolności (1977). W 1980 roku Karpiński napisał esej W Central Parku na temat artystów tworzących polską kulturę emigracyjną i zagraniczną. Kolejne jego utwory podejmujące podobną problematykę to m.in.: Książki zbójeckie (1988), Herb wygnania (1982), Twarze (2012). Jest autorem biografii artystycznych: Fajka van Gogha (1994), Portret Czapskiego (1996).

${ }^{4}$ Szkic ten został niepoprawnie podpisany przez redakcje „Kultury” nazwiskiem Tomasz Staliński (był to pseudonim Stefana Kisielewskiego, który pomagał w przekazaniu tekstu do publikacji). Wojciech Karpiński teksty publikował też pod pseudonimami: Jacek Salski i Kazimierz Opaliński. 
Przygotował również do druku francuski wybór pism Józefa Czapskiego L’Art et la vie (2002) i listy Konstantego Jeleńskiego do Józefa Czapskiego zatytułowane Listy z Korsyki (2003), francuskojęzyczny album Krzysztof Jung: Peintures, dessins, photographies (2017). W 2016 roku napisał wspomnienie Henryk, poświęcone Henrykowi Krzeczkowskiemu. W 1982 roku ukazała się książka Pamięć Włoch, w której opisał swoją pierwszą podróż na Półwysep Apeniński. W 1972 roku podczas pobytu w Rzymie poznał Miriam Chiaromonte, wdowę po włoskim pisarzu Nicoli Chiaromontem. W bibliotece przy via Ofanto po raz pierwszy przeczytał notatki włoskiego myśliciela: „Spotkaniu z jego tekstami towarzyszyła chęć rozmowy, jakby mówił specjalnie do mnie, o rzeczach ważnych, a zazwyczaj przemilczanych" (Karpiński 2012, 42). Karpiński scedował na grunt polskiej kultury twórczość autora Silenzio e parole i napisał na ten temat kilka szkiców oraz rozpraw ${ }^{5}$, jak również przyczynił się do sprowadzenia w 1992 roku przez Vincenta Giroud archiwum Chiaromontego do Beinecke Library. Temat podróży Wojciech Karpiński kontynuuje również w książkach Amerykańskie cienie (1982) i Obrazy Londynu (2014).

W latach osiemdziesiątych opracował rozmowy-rzeki z Leszkiem Kołakowskim i Alainem Besançonem. Wygłosił także laudację z okazji wręczenia Leszkowi Kołakowskiemu Europejskiej Nagrody Erasmus Prize (została ona opublikowana w European Liberty. Four Essays on the Occasion of the $25^{\text {th }}$ Anniversary of the Erasmus Prize Foundation. Raymond Aron, Isaiah Berlin, Leszek Kołakowski, Marguerite Yourcenar, Haga 1983) ${ }^{6}$. Karpiński poprzez internalizację „obcej mowy” wzmacniał swój głos. Ukazywał swoje myśli, idee, wartości na tle tekstów wygłoszonych czy napisanych przez „nie-Ja”. Konstatował, że mowa żywa to ekspresja, otwarcie etyczne ku Innemu, odpowiedź na refleksję, wezwanie czy stawiane wymagania.

Filozofia Paula Ricoeura stanowi propozycję lepszego zrozumienia najważniejszych zagadnień antropologicznych, dostarcza aparatu po-

${ }^{5}$ Zob. Trygar 2019, 73-84; Trygar 2019, 10-22; Trygar 2020, 36-51.

${ }^{6}$ Informacje na temat biografii Wojciecha Karpińskiego pochodzą ze strony: Wojciech Karpiński, biogram: http://www.wojciechkarpinski.com/biogram [dostęp: 17.01.2021]. 
jęciowego do analizy podmiotowości. Francuski myśliciel w pracach: Finitude et culpabilité. Philosophie de la volonté 2, cz. 1: L'Homme faillible (1960), Język, tekst, interpretacja. Wybór pism (1989), Filozofia osoby (1992), Autrement. Lecture d'Autrement qu'être ou Au-delà de l'essence d'Emmanuel Lévinas (1997), Histoire et vérité (2001); O sobie samym jako innym (2003), Anthropologie philosophique. Écrits et conférences (2013) pisze o podmiocie dialektycznym, otwartym, dynamicznym. Jedną z cech konstytuujących „tego-który-jest-sobą” jest bycie we wspólnocie. To znaczy, że rozumienie i rozpoznanie siebie jest możliwe tylko dzięki pośredniczącej roli kultury, literatury, historii, języka.

Droga do zgłębienia pisarstwa Karpińskiego zaczyna się od pytań: których z wielkich artystów i jakie dzieła autor sobie przypomina. Kategoria Anamnésis jest ściśle zespolona z czasem, co Karpiński potwierdził w intytulacji książki 120 dni „Kultury”. 120 dni uporządkowały jego sposób myślenia o świecie artystycznym, innych pisarzach, powołaniu do bycia artystą. Czas dla autora Herbu wygnania był związany z ruchem, porządkował wydarzenia świata, stał się zasadą racjonalności układu, tworzenia i przemian zachodzących w otaczającej rzeczywistości i świecie artystycznym. Warto zwrócić uwagę na kolejność i tytuły poszczególnych rozdziałów: U początków, następnie Pojawienie sie Gombrowicza i Miłosza; O wygnaniu; Czwarta polszczyzna i nowe oczy; Moment spełnienia (lato 1963); Gwiazdozbiór Witolda Gombrowicza, Gwiazdozbiór Witolda Gombrowicza (II), Gwiazdozbiór Czesława Miłosza, Gwiazdozbiór Józefa Czapskiego, Gwiazdozbiór Konstantego Jeleńskiego, Gwiazdozbiór Gustawa Herlinga-Grudzińskiego, Gwiazdozbiór Jerzego Stempowskiego, Gwiazdozbiór Wacława A. Zbyszewskiego, konsekutywnie O malarstwie; Poezja; Polityka; Portrety. Struktura narracyjna książki Karpińskiego łączy dwa procesy - działania i budowania postaci, wskazując, że rozumienia podmiotu nie można oddzielić od rozumienia jego doświadczeń, co ma wpływ na tożsamość i przedstawioną historię. Opowiadać to mówić, kto i co zrobił, z kim się spotkał, czego doświadczył. To sprawia, że czyjaś historia nie jest tylko przypadkowym powiązaniem ze sobą wydarzeń, lecz stanowi zorganizowaną koherentną całość. 
Świadomość - kim jest i kim chce być - uzyskał Karpiński w narracji, która wyznaczyła logikę procesu samorozumienia. Narracyjność ta ukazała sposób, w jaki porządkował swoje doświadczenia artystyczne (literackie) i projektował swoje przyszłe działania, ujawniając tym samym równoległy proces odkrywania siebie jako artysty $\mathrm{z}$ interpretacją (rozumieniem) dzieła literackiego:

Wypisywałem szczególnie cenne dla mnie fragmenty tekstów. Ich sekretna lektura powodowała przyśpieszone bicie serca, gdy zbliżałem się do dwudziestki, zachowują siłę oddziaływania po sześćdziesięciu latach. Powstało kompendium bliskich mi „złotych gwoździ”, po które dzięki internetowi sięgnąć można w dowolnym miejscu na ziemi, biblioteka idealna literatury i wirtualne drzewo genealogiczne kultury. Chciałbym, aby te teksty stały się dla innych tym, czym były dla mnie w młodości i czym pozostają w późnych latach (Karpiński 2020, 10).

Pojęcia narracyjnej tożsamości jednostki i wspólnoty Ricoeur zdefiniował jako dynamiczny model tożsamości, w którym jedność nie odnosi się do spójności substancjalnej, lecz do narracyjnej koherencji osoby (Warmbier 2018, 83) ${ }^{7}$. Tak ujęta podmiotowość pisarza pozostaje otwartym zagadnieniem i domaga się twórczej interpretacji.

Tworzenie tożsamości artysty przebiega w nieustannym spotkaniu z Innym. Bez spotkania nie istnieje "Ja", ów drugi mówi, dzieli się swoimi refleksjami, doświadczeniami, wskazuje na to, co wartościowe.

${ }^{7} \mathrm{~W}$ artykule odwołuję się przede wszystkim do rozważań zawartych w rozdziałach: Spór o podmiot w filozofii, s. 23-37; Część pierwsza. Między naturą a wolnością: Filozofie podmiotu i hermeneutyka siebie, s. 77-84; Część trzecia: Etyczne określenie Bycia sobą. Pamięć, Tożsamość i Inny, s. 265-281.

${ }^{8}$ Pojęcie „Ja" oznacza tożsamość. Odkrywanie jej następuje podczas spotkania z Innym człowiekiem. Podmiotowość człowieka kształtuje się pod wpływem różnych czynników, przede wszystkim kultury, literatury, filozofii i sztuki. Terminem bliskim słowu „Ja” jest „sobość” - oznacza to, co rdzenne w człowieku, co stanowi jego istotę, wartość. Zob. Husserl 1967, Kant 1970, Heidegger 1982, Jacques 1982. 
Świadomość kształtuje się i pogłębia w procesie poszukiwania przez pisarza swojego „Ja” i dopiero na pewnym etapie życia staje się decydującym czynnikiem. Na początku tej drogi jest tylko rozumienie w Heideggerowskim znaczeniu, które w książce Bycie i czas ma preontologiczny charakter i oznacza, że "Ja" nie jest obojętne na "bycie” i swoje powołanie (Heidegger 1999, 206-207). Należy ono do struktury Dasein i przebiega zawsze w hermeneutycznym kole. Podmiot wychodzi od „siebie” i „dociera” do siebie, przechodząc przez krytyczne zapośredniczenia w tekstach. Paul Ricoeur wyjaśnia to w następujący sposób:

Concernant le vocable „reconnaître”, qui sert ici de mise à l'épreuve des conceptions lexicographiques, les idées mères sont réduites au nombre de trois. I. Saisir (un objet) par l'esprit, par la pensée, en reliant entre elles des images, des perceptions qui le concernent; distinguer, identifier, connaître par la mémoire, le jugement ou l'action. II. Accepter, tenir pour vrai. III. Témoigner par de la gratitude que l'on est redevable envers quelqu'un de (quelque chose, une action) (Ricoeur 2004a, 30).

Ricoerowska koncepcja języka jako medium doświadczenia hermeneutycznego, została zaczerpnięta od Martina Heideggera, który dowiódł tezy o ścisłym zespoleniu myśli i bytu. Karpiński wydarzenia artystyczne i związane z nimi emocje ujmuje w kategoriach następujących po sobie sekwencji, których konfiguracja wymaga przekształcenia w całość znaczącą. W ten sposób poszerza się samowiedza „tego-który-jest-sobą”, który konstytuuje siebie jako „dzieło czytania i interpretacji” (Ricoeur 2005, 49). Warto w tym miejscu przytoczyć słowa Konstantego

${ }^{9} \mathrm{~W}$ przytoczonym fragmencie Ricoeur zwraca uwagę na słowo „rozpoznać”. Pojęcie to należy zredukować do trzech najważniejszych znaczeń: I. Uchwycenie (przedmiotu) przez umysł; w myślach powstają obrazy dzięki percepcji, która pozwala: rozróżniać, identyfikować, poznawać poprzez pamięć, osąd lub działanie. II. Zaakceptowanie i podtrzymywanie (pewnego stanowiska, poglądu). III. Okazanie wdzięczności komuś za „coś” (np. za jakieś działanie, wpływ). 
Jeleńskiego pochodzące ze szkicu Bohaterskie niebohaterstwo Gombrowicza opublikowanego w „Kulturze” 1957, nr 9/119:

Mimo że celem Dziennika jest odważne przedsięwzięcie natury moralnej, Gombrowicz wie, że jeśli się już wybrało słowo, ostateczną miarą odwagi i moralności jest styl. Na nic się zdadzą w literaturze najbardziej karkołomne doświadczenia wewnętrzne, jeśli nie towarzyszy im napięta, skupiona wola ich przekazania, osiągnięcia komunikacji. (...) W Dzienniku Gombrowicz odkrywa niemal wszystkie swoje karty, dokonuje szczodrego i odważnego daru samego siebie (Jeleński 1957, 36. Zob. Karpiński 2020, 36).

Dzieła literackie pisarzy, które były w centrum zainteresowania Karpińskiego przyczyniły się do jego pogłębionej refleksji nad podmiotowością, ponieważ odkrył w nich uzewnętrznienie dusz artystów. Poprzez utwór może narodzić się wspólnota "Ja" i „Ty", ponieważ kultura, w której zanurzony jest wytwór artystyczny, jest pierwotnym fenomenem źródłowej intersubiektywności, umożliwiając indywidualizację (Dilthey 1993, 49).

Philosophe, partenaire - terme qu'il affectionne - de l'action et de la culture, Paul Ricœur est un penseur du milieu entendu non seulement au sens de la mesôtes aristotélicienne, mais au sens de la médiation, de l'espace dialogique, du milieu de vie et d'habitation (Lebenswelt), enfin du milieu entendu comme espace éthique et politique (Resweber 2011, 1) ${ }^{10}$.

Ricoeur użył interesującego zwrotu soi-même comme un autre, wskazując, że relacja „Ja-Inne” jest konstytutywną kategorią antropologiczną (Ricoeur 2003b, 18-19).

${ }^{10}$ Resweber zauważa, że filozof jest zaangażowany nie tylko w świat kultury, ale także prowadzi dialog ze światem etyki i polityki. Paul Ricoeur jest filozofem podejmującym zagadnienie świata, rozumianego nie tylko w sensie arystotelesowskiego mesôtes, ale także Lebenswelt. 
La philosophie de Paul Ricœur mérite d'être fréquentée à plus d'un titre. D'abord, parce qu'elle est le fruit d'une démarche originale: Ricœur entend faire de la philosophie, c'est-à-dire retraverser, reprendre, réinterpréter les thèses d'Aristote, de Platon, de Rousseau, de Nabert, de Husserl, de Heidegger, de Gadamer, pour répondre à des questions anthropologiques, épistémologiques, éthiques et politiques (Resweber 2011, 1) ${ }^{11}$.

Autor Autrement. Lecture d'Autrement qu'être ou au-delà de l'essence d'Emmanuel Lévinas konstatował, że nie ma tu na myśli fichteańskiej koncepcji „Ja”-„nie Ja” i „Ja” i „nie-Ja” jako korelatu relacji dialektycznej. Idea soi-même comme un autre stanowi rozszerzony wariant terminu soi (bycia sobą), ukazując konstytutywną zależność dialektyczną dwóch fundamentalnych składowych podmiotu: „siebie” i „inności” (rozumienie siebie dokonuje się poprzez nieustanne odnoszenie się do tego, co inne) (Ricoeur 2003b, 19). Zaproponowana przez francuskiego filozofa koncepcja otwartej dialektyki łączy zatem dwa podejścia. Przyjmuje porządek aposterioryczny, wychodząc od konkretu - czyli jednostkowego podmiotu umiejscowionego w określonych realiach życiowych, w danej kulturze, posiadającego własną historię i doświadczenia - po kantowski gest, prowadzący refleksję o podmiocie w perspektywie transcendentalnej. Karpiński to zaangażowany uczestnik procesu „interpretacji” (rozumienia) dzieł „wielkich pisarzy”, oczywiście nie ustanawia jego początku, lecz dzięki konfrontacji z tekstami kultury ma możliwość ujęcia podstaw tego procesu. „Il existe donc une herméneutique spécifique à la méthode de la phénoménologie qui repose sur la partition du montrer/ cacher, dévoiler/voiler, décrypter/crypter" (Resweber 2011, 4) ${ }^{12}$.

${ }^{11}$ Resweber podkreśla, że filozofia Paula Ricoeura zasługuje na to, aby była odczytywana wieloaspektowo. Ricoeur wypracował swoją oryginalną koncepcję filozoficzną, odwołując się i reinterpretując myśli i idee Arystotelesa, Platona, Rousseau, Naberta, Husserla, Heideggera, Gadamera, aby odpowiadać na pytania stawiane przez antropologię, epistemologię, etykę i politykę.

12 „Istnieje hermeneutyka, która korzysta z metod fenomenologii opartych na podziale: pokaż/ukryj, ujawnij/zasłoń, odszyfruj/zaszyfruj”. Tłum. własne - B.T. 
Cechą konstytutywną tekstu Karpińskiego jest przeplatanie się warstwy semiotycznej i semantycznej, a praktyka obcowania z językowymi formami kultury pozwala mu ukierunkować przeżycia i doświadczenia:

Żyjemy w czasach, gdy po raz pierwszy korzystanie ze skarbów kultury nie jest elitarnym przywilejem wąskiej grupy bogatych i nie wymaga niezwykłego wysiłku. Od nas zależy, czym się będziemy interesować, co weźmiemy do czytania. To jest kwestia wolnego wyboru - i siły woli. Możemy budować własny swobodny i suwerenny dom Kultury, dom pamięci i wyobraźni (Karpiński 2020, 11).

Doświadczenie lektur innych pisarzy było dla Karpińskiego czymś wyjątkowym i niepowtarzalnym. Teksty te stały się dla niego darem, z którego obficie korzystał. Souvenirem niezmiernie poszukiwanym, ponieważ od artystów z kręgu paryskiej „Kultury” uczył się, co znaczy być prawdziwym „pisarzem, eseistą, krytykiem”. Autora Pamięci Włoch można nazwać przedstawicielem humanizmu dialogowego: „Hofmannsthal pisze, że we wszelkim »wyższym myśleniu «tkwi cud wspólnoty, jedności dnia dzisiejszego z przeszłością" (Karpiński 2020, 250). Humanizm Karpińskiego wykraczał poza granice jednego etnosu, poprzez kontakty z różnymi językami, kulturami i ideami kształtował siebie, tworzył swój warsztat pisarski i włączył się w powszechną wspólnotę artystyczną. Istotne dla Karpińskiego stały się słowa z artykułu „Ja” Józefa Czapskiego wydanego w „Kulturze” 1949, nr 15:

Do tych paru książek-wyznań, rozrzuconych na przestrzeni stu kilkudziesięciu lat, jestem również supersticieusement attaché comme à mes amours, odczuwam je również jak część własnej biografii. Te dzienniki, te kartki z notatników, francuskie, polskie, rosyjskie, karmiły mnie, uczyły, towarzyszyły wewnętrznie, (...) czy dodawały otuchy. Kiedyś chciałbym o tym świecie napisać szerzej... (Czapski 1949, 43. Zob. Karpiński 2020, 20).

Książka 120 dni „Kultury” jest nie tylko doświadczeniem językowym, artystycznym, ile swojego rodzaju spektaklem intertekstualnym, „pi- 
smem wywiedzionym z lektury pism". Sposobem racjonalizacji transgatunkowego, niesubordynowanego zjawiska było utożsamienie go z tekstowym zapisem „reakcji człowieka na rzeczywistość” (Kowalczyk 1990, 7). Dlatego wybór filozofii rozumienia według Ricoeura był tak istotny:

Comprendre, c'est comprendre le sens d'un texte dont, en dépit de la distance qui nous sépare de lui, nous recevons le message sur la base d'un sentiment d'appartenance au monde dont il témoigne. Comprendre, c'est pouvoir interpréter la chose-texte, selon l'expression de Gadamer, à partir des effets qu'elle produit sur la conscience (Wirkungsgeschichtliches Bewusstsein). L'herméneutique nous permet de faire anamnèse de notre milieu de vie, milieu qui est aussi celui de notre devenir (Resweber 2011,4) ${ }^{13}$.

Moment rozpoznania dokonuje się zdaniem francuskiego filozofa dzięki trwaniu śladów pamięciowych będących pozostałością pierwotnego wrażenia-doznania. Proces odkrywania „Ja” Karpińskiego dokonuje się w konfrontacji ze światem innych pisarzy, polegającej na przyjmowaniu wartości, norm, ideałów ważnych dla nich, w których wspólnota artystyczna się rozpoznaje. Potwierdzają to słowa Józefa Czapskiego zawarte w artykule „Ja”, przywołane przez Karpińskiego w książce 120 dni „Kultury”:

Chcę dziś mówić o tej formie literackiej, gdzie „ja” jest nie do uniknięcia, o pisarzach, dla których ta (...) mieszanina problemów najbardziej generalnych z przeżyciami najbardziej intymnymi, była stylem ich myślenia i odczuwania. Chciałbym tu zastosować w zwężonym zakresie zdanie z pa-

${ }^{13}$ Resweber postuluje, że rozumieć to rozumieć znaczenie tekstu. Pomimo dzielącej nas granicy mamy poczucie przynależności do świata, który on przedstawia. Zrozumieć to umieć zinterpretować tekst na podstawie skutków, jakie wywołuje w świadomości (Wirkungsgeschichtliches Bewusstsein), używając wyrażenia Gadamera. Hermeneutyka jest nauką, która dostarcza narzędzi, aby dogłębnie poddać analizie środowisko życia, w którym obecnie żyjemy i będziemy żyć. 
miętnika Brzozowskiego: „co nie jest biografią - nie jest w ogóle” (Czapski 1949, 43. Zob. Karpiński 2020, 20).

Martin Heidegger w książce Bycie i czas konstatował, że czas jest horyzontem bycia, bycie ofiaruje czas, czas ofiaruje bycie. Fenomen czasu, w jego źródłowym sensie, jest powiązany z pojęciem świata (Weltgegriff), a przez niego z samą strukturą Dasein (Heidegger 1994, 288, 360). Karpiński w analizowanej pracy dowiódł, że czas jest czasem „czegoś” i „dla kogoś”: „au stade initial de notre parcours, le »quoi« auquel la reconnaissance fait référence reste indifférencié; déjà, au plan lexical, la définition princeps évoquée plus haut parle de saisir par l'esprit »un objet«, autrement dit un "quelque chose«" (Ricoeur 2004a, 43) ${ }^{14}$. Czas pozwala wypełnić brak, aby zrodziło się coś dobrego i pięknego. Nie jest więc czymś zewnętrznym wobec duszy, jest on „wewnątrz” stworzonego przez nią świata, a zatem i w każdym z nas. Dusza nie zamyka się w sobie, ponieważ to upływ czasu otwiera ją na to, co inne. Przynosi jej nadzieję, jest gwarantem drogi, która wiedzie ku prawdziwym źródłom. Karpiński w książce 120 dni „Kultury” przywołał Dzienniki Witolda Gombrowicza, publikowane w „Kulturze” 1953, nr 9/71, akcentując, jak czas ukierunkowuje podmiot na to, co lepsze:

Polemizując z jednym z wcieleń Miłosza, Gombrowicz podejmuje na poziomie fundamentalnym dyskusję o roli wolnego słowa. „Nie domagam się ani sztuki stosowanej, ani czystej - domagam się twórczości »naturalnej«, takiej, która jest niepremedytowanym urzeczywistnieniem się człowieka" (Karpiński 2020, 30).

Podmiotowość to zwrócenie się ku Innemu, Inny tym samym to transcendowanie siebie. Karpiński podjął jeden z kluczowych w literaturze pięknej dyskursów na temat człowieka. Warto przywołać

${ }^{14}$ „Na początku naszej wędrówki badania terminu »rozpoznanie«, należy zacząć od zwrotu »co«, który pozwoli uchwycić przez umysł dany przedmiot; czyli »co« jest ważne dla »kogoś«". Tłum. własne - B.T. 
w tym miejscu słowa Michała Bachtina: „Z mojego jedynego miejsca otwiera się podejście do całego jedynego świata, a dla mnie wyłącznie z tego miejsca" (Bachtin 1997, 73). W tym świecie ważną rolę odgrywają: „Ja-dla-siebie”, „inny-dla mnie”, „Ja-dla innego”. Autor Szkiców amerykańskich przełożył perspektywę antropocentryczną nad ontologiczną i epistemologiczną. Wszelkie relacje czasowe i przestrzenne odnoszą się do rzeczywistego, konkretnego „wartościującego” centrum ludzkiego oraz układają się w stabilną, konkretną, „architektoniczną całość” (Bachtin 1997, 82). Jak podkreślił Karpiński: „Taki mną kierował cel: wsłuchując się w swobodne głosy innych, obronić i wzmocnić własny głos, a przez to dochować wierności mistrzom wybranym za młodu” (Karpiński 2020, 11). Przynależność do określonej wspólnoty to jeden $\mathrm{z}$ sensów pojęcia inności, wyrażonej w formule „ten-który-jest-sobą-samym-jak-i-innym”. W konsekwencji bycie częścią pewnej zbiorowości rozumiane jest jako jeden z podstawowych warunków umożliwiających samookreślenie. Sytuację tę dobrze oddaje mowa Witolda Gombrowicza wygłoszona „do narodu na bankiecie w gościnnym domu pp. X, u schyłku A.D. 1953”, opublikowana w „Kulturze" 1954, nr 1/75-2/76:

Nauczcie się dźwigać własne przeznaczenie. Wiedzcie, że ojczyzna wasza to nie Grójec ani Skierniewice, nawet nie kraj cały, i niech krew uderzy wam na policzki rumieńcem siły na myśl, że ojczyzną waszą wy sami jesteście! (...) W tej walce o głębszy sens życia i jego piękność nie jesteście osamotnieni. Na szczęście macie przy boku sztukę polską, która dziś stała się czymś ważniejszym i prawdziwszym (...) ona to, sztuka, nauczy was głębi. Ona, sztuka, otworzy wam oczy na ostrą piękność współczesności, na wielkość waszego zadania, a zbyt prowincjonalne uczucie zastąpi uczuciem nowym, na miarę świata, na miarę tych horyzontów, które dziś się przed wami otwierają (Gombrowicz 1954, 37-38. Zob. Karpiński 2020, 44).

W akcie czytania przez Karpińskiego „Kultury” mamy do czynienia z przejściem od prefiguracji, czyli doświadczenia ludzkiej aktywności, poprzez opowieściową konfigurację do refiguracji czasowego doświad- 
czenia w świecie czytelnika (Warmbier 2018, 191). Ważna jest konstatacja dotycząca samorozumienia i otwarcia się na tekst:

D'abord, la compréhension nous ouvre au texte en anticipant nos possibilités d'existence. À la chose du texte se trouve substitué le monde du texte qui se déploie devant nous. Ensuite, P. Ricœur se refuse à séparer l'explication de la compréhension, Interpréter ne consiste pas à opérer un fondu-enchaîné entre l'horizon du lecteur et celui du texte: c'est avant tout ouvrir l'homme au monde de ses possibilités, en lui permettant de s'anticiper. Le monde du texte s'inscrit dans la marge du texte, dans l'écart délivré par l'interprétation, écart qui est l'ébauche d'un milieu (Resweber 2011, 6) ${ }^{15}$.

Karpiński zastanawia się nad warunkami spotkania narracyjnych konfiguracji i etapu refiguracji, stanowiącej dialektyczne ukonstytuowanie w ramach przyswojenia. Odpowiedzią są słowa, które wypowiedział Konstanty Jeleński do Józefa Czapskiego podczas spaceru w Muzeum w Luwrze:

Znaki Twego Malarstwa pomogły rozpoznać inne znaki zaledwie przeczute w półmroku zmysłów, mimowolnej pamięci wyobraźni. Twoje dzieło bliskie jest nam jako drogowskaz do nieuchwytnych chwil uprzywilejowanych naszego życia (Jeleński 1976, 3-4. Zob. Karpiński 2020, 254).

Warto tu przypomnieć konstatację Ricoeura na temat odczytywania znaków: „Signe de reconnaissance, par lequel des personnes qui ne se

${ }^{15} \mathrm{~W}$ przytoczonym cytacie badacz stwierdza, że rozumienie otwiera nas na tekst, antycypując nasze możliwości istnienia. Czasami jedna tylko rzecz (wydarzenie) opisana w tekście wystarczy, aby otworzył się przed nami cały świat tekstu. P. Ricoeur nie oddziela wyjaśnienia od rozumienia: interpretacja nie polega na przenikaniu między horyzontem czytelnika a horyzontem tekstu: jest to przede wszystkim otwarcie człowieka na świat i jego możliwości, pozwalając mu antycypować siebie. Świat tekstu pozostawia wolną przestrzeń dla interpretacji, ta wolna przestrzeń jest zarazem medium. 
connaissent pas (ou qui ne se sont pas vues depuis longtemps) peuvent se reconnaître" (I, 2) (Ricoeur 2004a, 33) ${ }^{16}$. Istotne jest w jaki sposób tekst, a dokładnie świat kreowany przez dzieło, które nie stanowi jedynie wytworu określonych reguł kompozycji literackiej, lecz niesie w sobie pewien porządek wartości i normy, przedstawia niepowtarzalne ujęcie różnych wymiarów ludzkiego doświadczenia. Obrazują to słowa Gombrowicza opublikowane w „Kulturze” 1966, nr 5/223:

Co radził pod wieczór życia ten, jak go wielu traktowało, buntownik i burzyciel, awangardzista i prześmiewca? Wrócił już z Argentyny, zwraca się do Europy ze swym „ostatnim słowem”: „Jak sprawić, żeby sztuka przestała być wyrazem naszej mierności, a z powrotem stała się wyrazem naszej wielkości, piękności, poezji? Oto mój program: Primo zdać sobie jak najboleśniej sprawę z naszego kapcaństwa. Secundo odrzucić wszelkie teorie estetyczne wyprodukowane w ciągu ostatnich lat pięćdziesięciu, a zmierzające ukradkiem do osłabienia osobowości; cały ten okres jest zatruty dążeniem do niwelacji wartości i ludzi, precz z nim! Tertio porzuciwszy teorie, zwrócić się do osób, do wielkich osobowości czasu minionego i w przymierzu z nimi odnaleźć we własnych naszych osobach wieczyste źródło polotu, natchnienia, rozmachu i wdzięku” (Gombrowicz 1966, 31. Zob. Karpiński 2020, 92).

Odkrywanie „Ja” i Innego dokonuje się poprzez interpretację znaków, symboli zawartych w dziełach. Czynność lektury, w której rozwija się samorozumienie, polega na spotkaniu świata rzeczywistego i świata czytelnika wraz z jego specyficzną czasowością i wielością różnorodnych doświadczeń.

Ricœur va donner à sa démarche herméneutique une dimension nouvelle en la transposant du champ du texte dans le champ des disciplines qui étudient les divers aspects de l'action humaine. Il peut dès lors considérer que

${ }^{16}$ „Znak rozpoznawczy, to znak dzięki któremu rozpoznają się osoby, które się nie znają (lub nie widziały się od dawna)". Tłum. własne - B.T. 
chaque discipline est une approche interprétative d'un même objet: l'agir humain (Resweber 2011, 10) ${ }^{17}$.

Dwa światy, Karpińskiego i „Kultury”, przeplatają się. Dzięki dialogowaniu stają się dobrem wspólnym. Paryska „Kultura” pozwoliła Karpińskiemu skupić się na sobie i odnaleźć siebie. Wyznaczyła bieg jego życia artystycznego, była miejscem spotkania Innego. Poszukiwał, zbierał rozrzucone teksty, interpretował, w ten świat cudzych myśli wnosił swoje ekspresje. Dialektyka rozwijała się na wielu płaszczyznach, miała ona miejsce $\mathrm{w}$ pamięci, w relacjach $\mathrm{z}$ Innymi, w kulturze, w artefaktach. „Ja” Karpińskiego nie jest „Ja” pochodzącym z cogito, podmiotem w pełni autonomicznym, który odcina się od rzeczywistości. Jest podmiotowością, która odkrywa swoje powołanie w perspektywie wydarzeń, rzeczy, innych osób, poprzez konkretne czyny, spotkania i dzieła.

Drogi rozpoznania twórczości Karpińskiego ukazują dialektyczną koncepcję podmiotu ufundowanego na dialogu „Ja” z Innym. To, co dzieło odsłania, zależy od głębi zawartego w nim sensu („myśli”), a także od wieloaspektowej interpretacji. Autor Pamięci Włoch dzięki twórczej interpretacji tekstów innych pisarzy miał zdolność odkrywania świata, odsłaniania i ujawniania czegoś, co w rzeczywistości jest najbardziej ukryte, najważniejsze i najbardziej istotne. Nie ma innego miejsca, które umożliwiłoby ukazania tej prawdy. Dlaczego tak się dzieje? „Recconaitre: Se remettre dans 'esprit, l'idee de quelqu'un de quelque chose que l'on connit'” (Ricoeur 2004a, 21) ${ }^{18}$. Sztuka jest domeną wartości nie tylko estetycznych, ale także etycznych, a w szczególności należy tu wskazać związek prawdy i piękna. Piękno jest naprawdę pięknem, gdy sięga najgłębiej, to znaczy odkrywa piękno „Ja” jako artysty zanurzonego w sztuce.

${ }^{17}$ Resweber podkreśla, że Ricoeur swojej koncepcji hermeneutycznej nadał nowy wymiar. Narzędzia hermeneutyczne pozwoliły mu nie tylko badać tekst, ale także zgłębić różne aspekty ludzkiego działania. Według filozofa interpretacja powinna stawiać za nadrzędny cel ludzkie poznanie.

${ }^{18}$ „Rozpoznać to znaczy powrócić w myślach do osób, które się znało czy się spotkało". Tłum. własne - B.T. 


\section{Literatura}

Bachtin M., 1997, W stronę filozofii czynu, tłum. Żyłko B., Gdańsk: Słowo/obraz terytoria. Czapski J., 1949, „Ja”, „Kultura”, nr 15, s. 42-50.

Dilthey W., 1993, Rozumienie i życie, w: Wokót rozumienia: studia i szkice z hermeneutyki, wybór i tłum. Sowiński G., Kraków: Wydawnictwo Naukowe Papieskiej Akademii Teologicznej, s. 39-54.

Gombrowicz W., 1953, Fragmenty Dziennika, „Kultura”, nr 9/71, s. 45-57.

Gombrowicz W., 1966, Fragmenty Dziennika, „Kultura”, nr 5/223, s. 25-34.

Heidegger M., 1999, Bycie i czas, tłum. Mizera J., Warszawa: Państwowe Wydawnictwo Naukowe.

Husserl E., 1967, Idee czystej fenomenologii i fenomenologicznej filozofii, t. 1. tłum. Ingarden R., Warszawa: Państwowe Wydawnictwo Naukowe.

Jacques F., 1982, Différence est subjectivité. Antropologie d'un de vue rationnel, Paris: Aubier. Jeleński K., 1957, Bohaterskie niebohaterstwo Gombrowicza, „Kultura”, nr 9/119, s. 31-42. Jeleński K., 1976, Z Józefem Czapskim w Luwrze, „Kultura”, nr 4/343, s. 3-8.

Kant I., 1970, Anthropologie du point de vue pragmatique, tłum. Foucault M., Paris: Libraire Philosophique de Landrange.

Karpiński W., 2012, Twarze, Warszawa: Zeszyty Literackie.

Kowalczyk A.S., 2000, Esej, w: Literatura polska. XX wieku. Przewodnik encyklopedyczny, Warszawa: Państwowe Wydawnictwo Naukowe, s. 154.

Ricoeur P., 1960, Finitude et culpabilité. Philosophie de la volonté 2, cz. 1: L’Homme faillible, Paris: Aubier.

Ricoeur P., 1986, À l'école de la phénoménologie, Paris: Vrin.

Ricoeur P., 1989, Język, tekst, interpretacja. Wybór pism, wybór i wstęp Rosner K., tłum. Graff P., Rosner K., Warszawa: Państwowy Instytut Wydawniczy.

Ricoeur P., 1992, Filozofia osoby, tłum. Frankiewicz M., Kraków: Wydawnictwo Naukowe Papieskiej Akademii Teologicznej.

Ricoeur P., 1997, Autrement. Lecture d'Autrement quêtre ou Au-delà de l'essence d'Emmanuel Lévinas, Paris: PUF.

Ricoeur P., 2001, Histoire et vérité, Paris: Seuil.

Ricoeur P., 2003a, Egzystencja i hermeneutyka. Rozprawy o metodzie, wybór, oprac. i wprow. Cichowicz S., tłum. Bieńkowska E. i in., Warszawa: Instytut Wydawniczy PAX. 
Ricoeur P., 2003b, O sobie samym jako innym, tłum. Chełstowski B., nauk. oprac. i wstęp Kowalska M., Warszawa: Państwowe Wydawnictwo Naukowe.

Ricoeur P., 2004a, Parcours de la reconnaisance, Paris: Stock.

Ricoeur P., 2004b, Drogi rozpoznania. Wykłady Instytutu Nauk o Człowieku, tłum. Margański J., Kraków: Znak.

Ricoeur P., 2005, Refleksja dokonana. Autobiografia intelektualna, tłum. Bobowska-Nastarzewska P., Kęty: Antyk.

Ricoeur P., 2013, Anthropologie philosophique. Écrits et conférences, Paris: Seuil.

Trygar B., 2019, Przeszłość - teraźniejszość - przyszłość, kai eleutheria - kai aletheia - kai agathon, Platon - Nicola Chiaromonte - Wojciech Karpiński (ontologiczno-aksjologiczne trójkąty), „Filologia Polska. Roczniki Naukowe Uniwersytetu Zielonogórskiego”, nr 5, s. 73-84.

Trygar B., 2019, „Euarmostia kai aglaja” w pismach Isaiaha Berlina, Nicoli Chiaromontego $i$ Wojciecha Karpińskiego, czyli filozoficzno-literacka triangulacja, „Głos-Język-Komunikacja”. Wartości i wartościowanie w XXI wieku, Tom 7, Rzeszów: Wydawnictwo Uniwersytetu Rzeszowskiego, s. 10-22.

Trygar B., 2020, „Nella cerchia degli incontri italo-polacchi”. Eseje Nicola Chiaromontego $w$ perspektywie teorii skopos, „Tematy i Konteksty”. Recepcja i przekład literatury polskiej, nr 10 (15), s. 36-51.

Warmbier A., 2018, Tożsamość, narracja i hermeneutyka siebie. Paula Ricoeura Filozofia człowieka, Kraków: Universitas.

\section{Netografia}

„Kultura” paryska: https://kulturaparyska.com/pl/index [dostęp: 12.04.2021].

Wojciech Karpiński, biogram, http://www.wojciechkarpinski.com/biogram [dostęp: 17.01.2021].

Karpiński W., 2020, 120 dni „Kultury”, http://www.wojciechkarpinski.com/120-dni-kultury [dostęp: 17.01.2021].

Resweber P., 2011, Ricoeur: philosophe du milieu, in: Paul Ricour: une anthropologie philosophique, „Revue de philosophie et de sciences humaines”, nr 11, https://journals. openedition.org/leportique/2504 [dostęp: 17.01.2021]. 
BARBARA TRYGAR - dr, Uniwersytet Rzeszowski, Rzeszów, Polska.

Trygar completed her PhD with honours in 2014 at the Faculty of Philology at the University of Rzeszów. She is the author of "Ja" w drodze do Wolności, Prawdy i Piękna. Aspekty aksjologiczne twórczości prozatorskiej Kazimierza Brauna (Rzeszów 2019), co-editor (together with Jolanta Pasterska) of Przeżycie - Doświadczenie - Kontemplacja. Pisarstwo Kazimierza Brauna (Rzeszów 2017), and author of over 40 interdisciplinary journal articles. Her research interests focus on identity and space in migrant and migration literature as well as Polish and foreign literature of the $20^{\text {th }}$ and $21^{\text {st }}$ centuries in the context of axiology, phenomenology, and (neuro)aesthetics. She is a member of Pracownia Badań i Dokumentacji Kultury Literackiej (Literary Culture Research and Documentation Centre) at the Institute of Polish Studies and Journalism at the University of Rzeszów.

Doktor nauk humanistycznych, w 2014 roku obroniła z wyróżnieniem rozprawę doktorską na Wydziale Filologicznym Uniwersytetu Rzeszowskiego. Jest autorką książki „Ja” w drodze do Wolności, Prawdy i Piękna. Aspekty aksjologiczne twórczości prozatorskiej Kazimierza Brauna (Rzeszów 2019), współredaktorką (z prof. dr hab. Jolantą Pasterską) książki Przeżycie - Doświadczenie - Kontemplacja. Pisarstwo Kazimierza Brauna (Rzeszów 2017), autorką ponad 40 artykułów o charakterze interdyscyplinarnym. Jej zainteresowania naukowe koncentrują się na zagadnieniach tożsamości i przestrzeni w literaturze emigracyjnej oraz migracyjnej, literaturze polskiej i obcej XX i XXI wieku w perspektywie badań aksjologicznych, fenomenologicznych, (neuro)estetycznych. Jest członkiem Pracowni Badań i Dokumentacji Kultury Literackiej w Instytucie Polonistyki i Dziennikarstwa Uniwersytetu Rzeszowskiego.

E-mail: barbara.trygar@poczta.onet.pl 